\title{
Comparison of ketamine-propofol and remifentanil in terms of hemodynamic variables and patient satisfaction during monitored anaesthesia care
}

\author{
Sema Oncul, Elif Atar Gaygusuz, Mehmet Yilmaz, Hasan Terzi, Canan Balci \\ Department of Anaesthesiology, Kocaeli Derince Education and Research Hospital, Kocaeli, Turkey
}

\begin{abstract}
Background: This study aimed to compare remifentanil and ketamine-propofol in terms of hemodynamic response, duration of recovery and patient satisfaction in operative hysteroscopy cases who underwent monitored anaesthesia care in combination with paracervical block.

Methods: Monitored anaesthesia care was used in 60 ASA I-II female patients. The patients were divided into two groups as remifentanil (Group R) and ketamine-propofol (Group K-P). The hemodynamic effects of remifentanil and ketamine-propofol, and duration of recovery were recorded and compared. The patient satisfaction was also recorded and the two groups were compared.

Results: Age, body mass, ASA status, duration of anaesthesia and type of surgery were found to be similar between groups. The time of the Aldrete score reaching $\geq 9$ was found to be shorter in Group $R$ when compared with Group KP (Group R: $4.1 \pm 1.9 \mathrm{~min}$, Group K-P: $6.1 \pm 2.6 \mathrm{~min})(P<0.05)$. The incidence of postoperative nausea and vomiting was found to be significantly higher in the remifentanil group $(P \leq 0.05)$. When the groups were compared in terms of patient satisfaction, in both groups this was found to be similar.

Conclusion: Sedation with remifentanil combined with a paracervical block during monitored anaesthesia care provides early recovery with effective sedation and analgesia in hysteroscopy procedures.
\end{abstract}

Key words: monitored anaesthesia care; opioids, remifentanil; sedatives, ketamine, propofol; outpatient surgery

Anaesthesiology Intensive Therapy 2016, vol. 48, no 2, 116-121

Hysteroscopy procedures are outpatient procedures that are usually done with a paracervical block [1]. An operative hysteroscopy procedure is usually performed due to polypectomy, endometrial ablation and myomectomy [2]. Although a hysteroscopy is a minimally invasive surgical procedure, as cervical dilatation and tissue extraction with a Hegar dilatator causes severe pain, usually short-term monitored anaesthesia care (MAC) or general anaesthesia is required [3-5]. The most commonly used intravenous agent for general anaesthesia or MAC is propofol. Although propofol provides dose-dependant sedation, amnesia and an anxiolytic effect, it requires an additional analgesic agent as it has no analgesic effect $[6,7]$. It is especially preferred in outpatient surgery, as it provides a short duration of recovery and early discharge from hospital. Another agent that may be preferred in outpatient surgery is ketamine which is effec- tive as a dissociative, sedative, analgesic, and amnesic agent. Ketamine protects muscular tonus and airway reflexes, and allows spontaneous respiration [8]. As the respiratory and hemodynamic effects of propofol and ketamine are antagonistic, combinations of these agents in low doses cause less dose-dependent adverse effects [9]. It has been shown that propofol and ketamine combinations in outpatient procedures are an effective and reliable method $[9,10]$.

One of the agents frequently used in monitored anaesthesia care is remifentanil. Being metabolized by nonspecific plasma and tissue esterases, the effect of remifentanil terminates in a short time, independent from the duration of administration [11, 12]. It has been shown that intravenously administered remifentanil in combination with paracervical block provides effective sedation and analgesia in operative hysteroscopies without any serious side effects [1]. 
In the present study we aimed primarily to compare types of hemodynamic response. Of secondary focus were duration of recovery, as well as patient satisfaction with ketamine-propofol and remifentanil during MAC that were administered in addition to a paracervical block in operative hysteroscopies.

\section{METHODS}

This prospective study was done in the Anaesthesiology Clinic of Kocaeli Education and Research Hospital after obtaining the ethics committee approval of Kocaeli University and written informed patient consent (Project Number: KOU KAEK 2012/107). There were included into the study 60 ASA I-II female patients, aged 18-60 years, undergoing operative hysteroscopy procedures (endometrial ablation, endometrial polyp or endometrial biopsy). The exclusion criteria were: $A S A \geq I I I$, patients with $B M I \geq 35 \mathrm{~kg}$ $\mathrm{m}^{-2}$, cerebrovascular, neurological or psychiatric disorders, uncooperative patients, patients with chronic sedative, analgesic or opioid use and those who had a history of allergy to local anaesthetics. The patients who had their preoperative evaluation were informed by the same anaesthesiologist and consent was obtained.

The patients were randomly divided into two groups as Group R (remifentanil) and Group K-P (propofol-ketamine). The random allocation sequence was generated by shuffling opaque, sealed envelopes. The study was designed with parallel groups and no blinding of patients or of outcome assessors. All patients were taken to the operating theatre after being pre-medicated with $0.05 \mathrm{mg} \mathrm{kg}^{-1}$ midazolam. Before induction monitoring of the ECG, MAP, $\mathrm{HR}$ and $\mathrm{SpO}_{2}$ and end-tidal $\mathrm{CO}_{2}$ were completed and the control values were recorded. The values during MAC were recorded at 5-minute intervals. $\mathrm{O}_{2}$ with face mask at a rate of $4 \mathrm{~L} \mathrm{~min}^{-1}$ was administered to all patients.

The Ramsey Sedation Scale (RSS) was used to determine the level of sedation in both groups (Table 1). The intraoperative sedation level was aimed to be RSS $=4$.

In Group R, $0.5 \mu \mathrm{g} \mathrm{kg}^{-1}$ remifentanil was administered as a bolus at 1 minute during anaesthesia induction and

Table 1. Ramsey Sedation Scale

\begin{tabular}{|c|c|}
\hline 1 & The patient is anxious and agitated or restless \\
\hline 2 & The patient is co-operative, oriented, and calm \\
\hline 3 & The patient responds to commands only \\
\hline 4 & $\begin{array}{l}\text { The patient is asleep but awakes with a glabellar tap or } \\
\text { auditory stimulus }\end{array}$ \\
\hline 5 & $\begin{array}{l}\text { The patient is asleep but exhibits a sluggish response to } \\
\text { a glabellar tap or auditory stimulus }\end{array}$ \\
\hline 6 & $\begin{array}{l}\text { The patient is asleep but exhibits a sluggish response to } \\
\text { a glabellar tap or auditory stimulus }\end{array}$ \\
\hline
\end{tabular}

was continued as an infusion at a dose of $0.5 \mu \mathrm{g} \mathrm{kg}^{-1} \mathrm{~min}^{-1}$ and step down according to RSS. It was then continued as an infusion at a dose of $0.1-0.5 \mu \mathrm{g} \mathrm{kg}^{-1} \mathrm{~min}^{-1}$ during MAC. The patient was taken to the lithotomy position when RSS was 4 . In both groups, paracervical block was performed with $10 \mathrm{~mL}$ of $1 \%$ lidocaine injection at the 5 and 7 o'clock positions of the cervix by the gynaecologist. One minute later, by dilating with a Hegar dilator number 9 , a $10 \mathrm{~mm}$ rigid hysteroscope was used throughout the procedure. The dose of remifentanil infusion was adjusted to obtain a target RSS of 4 during the procedure.

In Group K-P, following the intravenous (i.v.) administration of $0.25 \mathrm{mg}$ atropine before anaesthesia induction to minimize the increased secretion effect of ketamine, anaesthesia induction was completed. Following the administration of $1 \mathrm{mg} \mathrm{kg}^{-1}$ propofol and $0.5 \mathrm{mg} \mathrm{kg}^{-1} \mathrm{ketamine}$ as an i.v. bolus for anaesthesia induction, the patient was taken to the lithotomy position. Similarly, the procedure began after a paracervical block. Throughout MAC, under the observation of the anaesthesiologist, $20 \mathrm{mg}$ propofol and $10 \mathrm{mg}$ ketamine were given as an i.v. bolus when needed, to achieve an RSS of 4 .

The doses of the drugs were increases when the precence of grinace, movement, pain, sudden increase in heart rate, or hypertension. In the presence of grimace, movement, pain, sudden increase in heart rate, or hypertension, the doses were increased. A respiratory rate less than 10 $\min ^{-1}, \mathrm{SpO}_{2} \leq 90 \%$ for more than $30 \mathrm{~s}$, and apnoea lasting longer than $20 \mathrm{~s}$ were accepted as respiratory depression. In those with respiratory depression the infusions were stopped and if the respiratory depression continued in spite of verbal and tactile stimulus, ventilation was maintained with a mask. A decrease of $25 \%$ or more than the control values for the intra-operative systolic blood pressure or MAP lower than $60 \mathrm{~mm} \mathrm{Hg}$ were accepted as hypotension. A heart rate lower than $45 \mathrm{~min}^{-1}$ was accepted as bradycardia and treated with $0.5 \mathrm{mg}$ atropine. During anaesthesia, ECG, non-invasive blood pressure and $\mathrm{SpO}_{2}$ follow-up was completed. The vital signs of the patients were monitored in the recovery unit following the procedure. Postoperative complications such as nausea, vomiting, strain, holding one's breath, laryngospasm, and desaturation were monitored until the patients were discharged from the recovery unit. The patients were dicharged from the recovery room to ward after their Modified Aldrete Score (MAS) was $\geq 9$ (Table 2).

Twenty-four hours after the operation, the patients were questioned about their anaesthesia experience $(0=$ good, 1 = intermediate, 2 = bad).

\section{STATISTICAL ANALYSIS}

A statistical analysis of the study was done using IBM SPSS Statistics 20. The Student's t test was used for numerical 
Table 2. Modified Aldrete Recovery Score (MAS)

\begin{tabular}{|c|c|c|}
\hline Activity (with command or volunteer movement) & $\begin{array}{l}4 \text { extremity } \\
2 \text { extremity } \\
0 \text { extremity }\end{array}$ & $\begin{array}{l}2 \text { points } \\
1 \text { point } \\
0 \text { point }\end{array}$ \\
\hline Respiration & $\begin{array}{l}\text { Able to deep breath, cough freely } \\
\text { Dyspnoea, shallow and limited breathing } \\
\text { Apnoeic }\end{array}$ & $\begin{array}{l}2 \text { points } \\
1 \text { point } \\
0 \text { point }\end{array}$ \\
\hline Circulation & $\begin{array}{l}\text { Blood pressure } \pm 20 \mathrm{~mm} \mathrm{Hg} \text { of pre-anaesthetic period } \\
\text { Blood pressure } \pm 20-50 \mathrm{~mm} \mathrm{Hg} \text { of pre-anaesthetic period } \\
\text { Blood pressure } \pm 50 \mathrm{~mm} \mathrm{Hg} \text { of pre-anaesthetic period }\end{array}$ & $\begin{array}{l}2 \text { points } \\
1 \text { point } \\
0 \text { point }\end{array}$ \\
\hline Consciousness & $\begin{array}{l}\text { Fully awake } \\
\text { Arousable on calling } \\
\text { No response }\end{array}$ & $\begin{array}{l}2 \text { points } \\
1 \text { point } \\
0 \text { point }\end{array}$ \\
\hline $\mathrm{O}_{2}$ saturation & $\begin{array}{l}>\% 92 \text { on room air } \\
\text { Needs } \mathrm{O}_{2} \text { inhalation to maintain } \mathrm{SpO}_{2}>90 \% \\
<\% 90 \text { with } \mathrm{O}_{2} \text { supplementation }\end{array}$ & $\begin{array}{l}2 \text { points } \\
1 \text { point } \\
0 \text { point }\end{array}$ \\
\hline
\end{tabular}

Table 3. Demographic and clinical data for each group

\begin{tabular}{lccc}
\hline & $\begin{array}{c}\text { Group 1 } \\
(\mathrm{n}=30)\end{array}$ & $\begin{array}{c}\text { Group 2 } \\
(\mathrm{n}=30)\end{array}$ & P value \\
\hline Age (year) & $42.2 \pm 9.3$ & $43.1 \pm 8.4$ & 0.6 \\
Weight (kg) & $71.2 \pm 17.0$ & $71.7 \pm 13.7$ & 0.9 \\
ASA (I/II) (n) & $23 / 7$ & $23 / 7$ & 1 \\
Duration of anaesthesia (min) & $22.0 \pm 7.4$ & $22.6 \pm 8.0$ & 0.7 \\
Duration of surgery (min) & $10.9 \pm 7.8$ & $14.1 \pm 7.5$ & 0.06 \\
Type of surgery (n(\%)) & & & \\
Endometrial ablation/biopsy & $16(53.3 \%)$ & $15(50 \%)$ & \\
Polypectomy & $14(46.7 \%)$ & $15(50 \%)$ & \\
\hline
\end{tabular}

Data are mean \pm SD or $n$; ASA - American Society of Anesthesiologists

data with a normal distribution, while the Mann-Whitney U-test was used for numerical data without a normal distribution. The paired-samples Student's t-test was used for intragroup comparisons. The results were evaluated with $95 \%$ confidence interval and with a significance level of $P<0.05$.

\section{RESULTS}

The age, body mass, ASA class, duration of anaesthesia and surgery, as well as the type of surgery performed were similar in both the examined groups $(P>0.05)$ (Table 3$)$.

When Group R and Group K-P values are compared with control MAP values; the decrease in Group $R$ at the postoperative first minute $(P=0.04)$ and the increase in MAP in Group K-P at postoperative $5^{\text {th }}$ minute $(P=0,01)$ were accepted as significant (Fig. 1). HR was found to be higher at the $5^{\text {th }}$ minute, the $10^{\text {th }}$ minute, the postoperative $1^{\text {st }}$ minute and after recovery in Group $\mathrm{R}$ in intragroup and intergroup comparisons (Fig. 2). A significant difference in respiratory rate (RR) and $\mathrm{ETCO}_{2}$ level after sedation was noticed between groups during surgery $(P<0.05)$ (Fig. 3).

Perioperative adverse effects demonstrated differences in both groups (Table 4). Although tachycardia and respira- tory depression was seen in five patients in Group R and in one patient in Group K-P, no statistically significant difference was found $(P=0.08)$. While hypertension was seen at an equal rate in both groups, hypotension was not observed in either group. Bradycardia was seen in only one patient in the ketamine-propofol group. In the evaluation of recovery with MAS, no difference was seen in the values at the first $(P=0.1)$ and fifth minute $(P=0.2)$ (Table 4). When the time to reach $M A S \geq 9$ in both groups were compared, the time was found to be shorter in Group R ( $P=0.1)$ (Fig. 4). Postoperative nausea and vomiting (PONV) was seen in only in eight patients the remifentanil Group R (Table 4).

The patients were questioned about their anaesthesia experience 24 hours after surgery. When they were asked to evaluate it as good-intermediate-bad, all patients in both groups evaluated their experience as "good".

\section{DISCUSSION}

This study demonstrated that sedation with remifentanil combined with a paracervical block provides effective analgesia in operative hysteroscopy procedures.

It is suggested that patients who are planned for hysteroscopy in outpatient clinics may reject this procedure due to their previous experience of pain. Carabias et al. [13] reported that although they performed paracervical anaesthesia in only $8 \%$ of outpatient hysteroscopy patients, $57 \%$ of them experienced moderate and severe pain. Although it was suggested that paracervical anaesthesia reduces the pain during outpatient hysteroscopy [1], local anaesthesia alone during these procedures resulted in more unpleasant events ending with conversion into general anaesthesia [5].

In many studies in different outpatient anaesthesia practices, sedation with remifentanil was used as a part of MAC in addition to local anaesthesia $[2,14,15]$. In surgeries of short duration, the pharmacokinetic properties of remifentanil provides rapid onset and recovery of its 


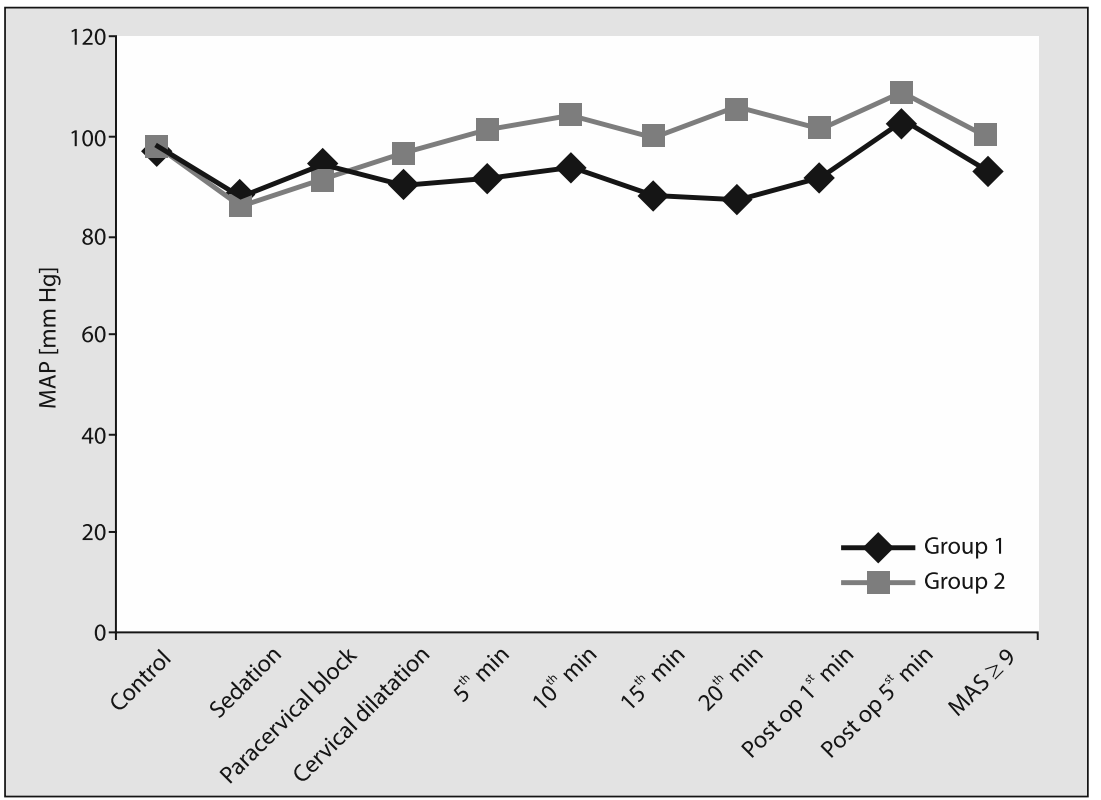

Figure 1. Mean arterial pressure (MAP)-time graphic

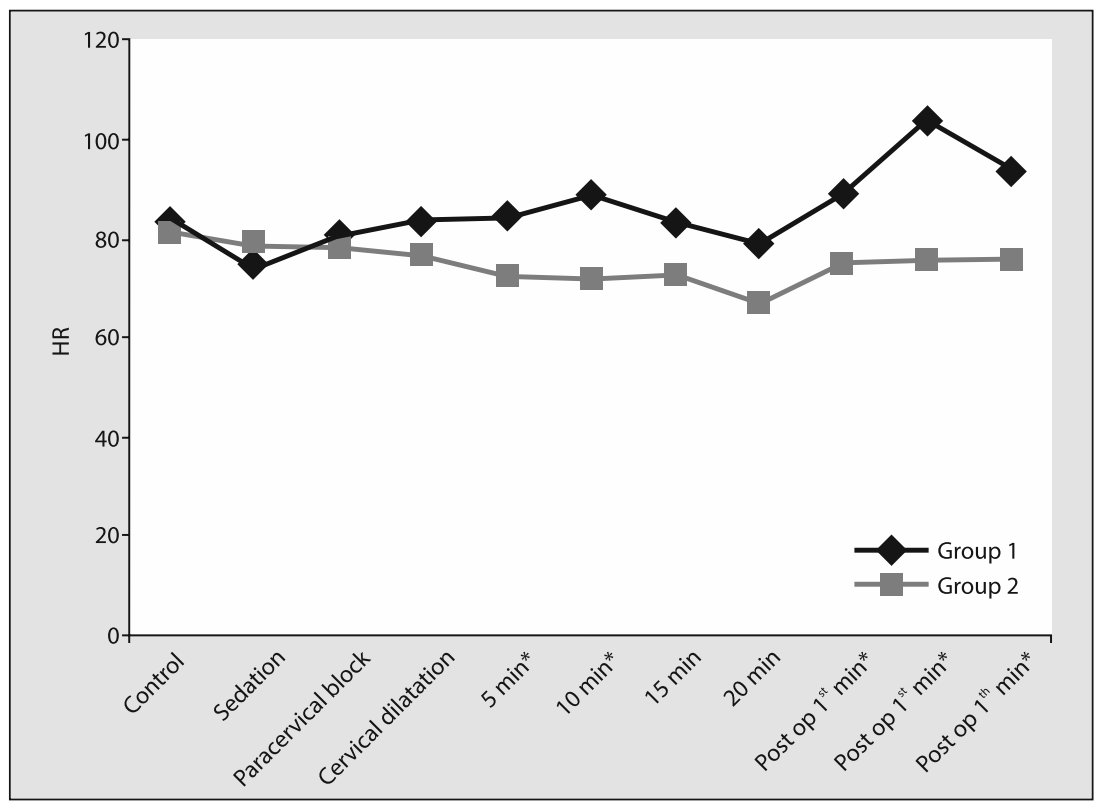

Figure 2. Heart rate (HR)-time graphic ( ${ }^{*} P<0.05$ : between groups comparison)

analgesic effect, and it also provides early recovery as it has a lower risk of postoperative respiratory depression. It has been shown that remifentanil infusion decreases the respiratory rate and decreases oxygen saturation $[3,14]$. In our study, although respiratory depression was seen in five patients in the remifentanil group (16.6\%) and in one patient in the ketamine-propofol group (3.3\%), no statistically significant difference was observed. This condition was easily controlled by decreasing the dose of the anaesthetic agents and by the jaw thrust manoeuvre or assisted ventilation when required. No respiratory depression was observed during the postoperative period in either group.

Majholm et al. [2] found that in hysteroscopy procedures in which remifentanil was combined with a paracervical block, mobilization and discharge was more rapid than total i.v. anaesthesia. In our study, although the time of recovery was seen two minutes lower with remifentanil sedation. Servin et al. showed that the rate of nausea was observed $27 \%$ during remifentanil sedation as an adjunct 


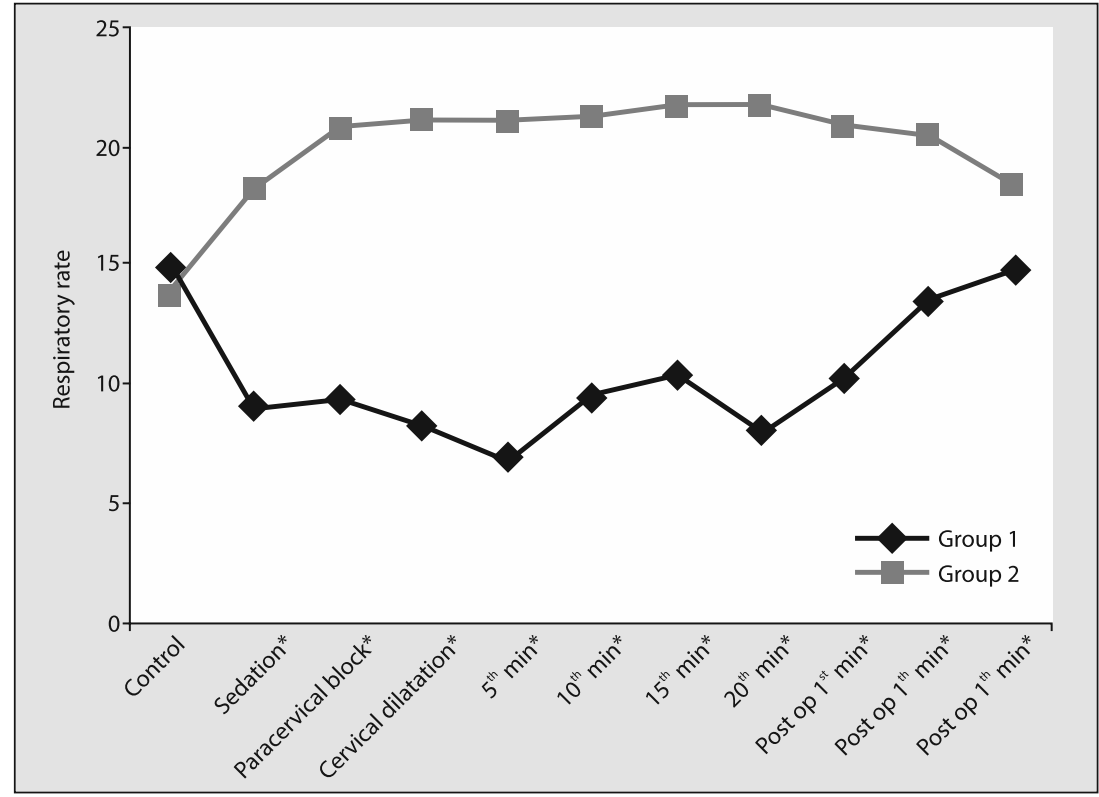

Figure 3. Respiratory rate-time graphic. ( ${ }^{*} P<0.05$ : between groups comparison)

Table 4. Perioperative adverse effects and recovery characteristics. Data given as mean \pm SD or $n(\%)$

\begin{tabular}{|c|c|c|c|}
\hline & Group 1 & Group 2 & $P$ value \\
\hline Hypotension (MAP < 60 mm Hg) & $0(0 \%)$ & $0(0 \%)$ & 1.0 \\
\hline Hypertension (SAP > 150 mm Hg) & $12(40 \%)$ & $12(40 \%)$ & 1.0 \\
\hline Bradycardia $\left(\mathrm{HR}<45 \mathrm{~min}^{-1}\right)$ & $0(0 \%)$ & $1(3.3 \%)$ & 0.7 \\
\hline Tachycardia $\left(\mathrm{KH}>110 \mathrm{~min}^{-1}\right)$ & $5(16.6 \%)$ & $1(3.3 \%)$ & 0.08 \\
\hline Respiratory depression & $5(16.6 \%)$ & $1(3.3 \%)$ & 0.08 \\
\hline Postoperative nausea-vomiting* & $8(26.6 \%)$ & $0(0 \%)$ & 0.003 \\
\hline Itching* & $5(16.6 \%)$ & $0(0 \%)$ & 0.02 \\
\hline \multicolumn{4}{|l|}{ MAS (n) } \\
\hline Post-op $1^{\text {st }} \min ^{*}$ & $6.7 \pm 1.2$ & $6.7 \pm 5.0$ & 0.1 \\
\hline Post-op $5^{\text {th }} \min$ & $7.6 \pm 0.5$ & $7.1 \pm 1.1$ & 0.2 \\
\hline MAS $\geq 9(\min )^{*}$ & $4.1 \pm 1.9$ & $6.1 \pm 2.6$ & 0.001 \\
\hline \multicolumn{4}{|l|}{ The total dose } \\
\hline Total remifentanil $(\mu \mathrm{g})$ & $478.9 \pm 186.4$ & & \\
\hline Total propofol (mg) & & $144.6 \pm 46.8$ & \\
\hline Total ketamine (mg) & & $72.4 \pm 23.4$ & \\
\hline
\end{tabular}

${ }^{*} \mathrm{P}<0.05$ between groups comparison; MAS - Modified Aldrete Recovery Score

to regional anesthesia. Another study found that a lower dose of remifentanil in combination with midazolam was associated with a reduced incidence nausea [14]. In our study, in spite of a higher dose of remifentanil, the rate of nausea and vomiting were found to be similar to the literature. Indeed, eight of the 30 patients (26.6\%) who had remifentanil suffered from nausea. These patients were treated with metoclopramide $\mathrm{HCl} 10 \mathrm{mg}$ i.v. Thus, the administration of standard prophylaxis of PONV in patients in which remifentanil infusion is to be used would be advantageous [2].

Ketamine is a frequently used agent for sedation, especially in children. The most frequently seen side effect is airway and respiratory effects, larygospasm, apnoea, nausea, and agitation occurring during recovery [17]. In the studies of Badrinath et al. [18] who combined different concentrations of ketamine and propofol during MAC, they showed that the increased concentrations of ketamine are 
associated with PONV, various psychotomimetic effects and prolonged recovery periods. In our study, while ketamine was used in a half dose of propofol, PONV was not observed in any patients in this group. This can be due to the direct antiemetic effect of propofol [19]. The recovery period was found to be longer in the ketamine-propofol group when compared with the remifentanil group. The time to reach MAS $\geq 9$ in this group was approximately 6 minutes, and was 4 minutes in the remifentanil group. However, we think this is clinically insignificant.

Akin et al. [20, 21] showed that propofol administration in combination with low dose ketamine maintains MAP, decreases the risk of respiratory depression, and requires a lower amount of additional doses. This is likely due to the stimulatory effect of ketamine on ventilation by sympathoadrenergic activation [22]. In our study, MAP was maintained similarly in both groups during surgery. Respiratory depression was seen in only one patient in the ketaminepropofol group.

In a meta-analysis by Green et al. [17], it was concluded that the addition of any kind of anticholinergic to ketamine decreases oral secretions and respiratory side effects. However, although in the current study, a low dose of atropine (0.25 mg) was administered for premedication, a cough reflex was seen in five patients in the ketamine-propofol group.

As a result of this study, it was found that remifentanil combined with a paracervical block provides more stable hemodynamic conditions in operative hysteroscopies when compared with ketamine-propofol combination. Although nausea and vomiting were seen in the postoperative period in the remifentanil group, no difference was seen either group in terms of patient satisfaction.

\section{ACKNOWLEDGEMENTS}

1. The authors declare no financial disclosure.

2. The authors declare no conflict of interest.

\section{References:}

1. Cooper NA, Khan KS, Clark TJ: Local anaesthesia for pain control during outpatient hysteroscopy: systematic review and meta-analysis. BMJ 2010; 340: c1130. doi: 10.1136/bmj.c1130.

2. Majholm B, Bartholdy J, Clausen HV, Virkus RA, Engbæk J, Møller AM: Comparison between local anaesthesia with remifentanil and total intravenous anaesthesia for operative hysteroscopic procedures in day surgery. Br J Anaesth 2012; 108: 245-253. doi: 10.1093/bja/aer337.

3. Ryu JH, Kim JH, Park KS, Do SH: Remifentanil-propofol versus fentanylpropofol for monitored anesthesia care during hysteroscopy. J Clin Anesth 2008; 20: 328-332. doi: 10.1016/j.jclinane.2007.12.015.

4. Sutton C: Hysteroscopic surgery. Best Pract Res Clin Obstet Gynaecol 2006; 20: 105-137.
5. Wallage S, Cooper KG, Graham WJ, Parkin DE: A randomised trial comparing local versus general anaesthesia for microwave endometrial ablation. BJOG 2003; 110: 799-807.

6. Mortero RF, Clark LD, Tolan MM, Metz RJ, Tsueda K, Sheppard RA: The effects of small-dose ketamine on propofol sedation: respiration, postoperative mood, perception, cognition, and pain. Anesth Analg 2001; 92: 1465-1469.

7. Willman EV, Andolfatto G: A prospective evaluation of "ketofol" (ketamine/propofol combination) for procedural sedation and analgesia in the emergency department. Ann Emerg Med 2007; 49: 23-30.

8. Bahn EL, Holt KR: Procedural sedation and analgesia: a review and new concepts. Emerg Med Clin North Am 2005; 23: 503-517.

9. Bowdle TA, Radant $A D$, Cowley DS, Kharasch ED, Strassman RJ, RoyByrne PP: Psychedelic effects of ketamine in healthy volunteers: relationship to steady-state plasma concentrations. Anesthesiology 1998; 88: 82-88.

10. Nejati A, Moharari RS, AshrafH, Labaf A, Golshani K: Ketamine/propofol versus midazolam/fentanyl for procedural sedation and analgesia in the emergency department: a randomized, prospective, doubleblind trial. Acad Emerg Med 2011; 18: 800-806. doi: 10.1111/j.15532712.2011.01133.x.

11. Glass PS, Hardman D, Kamiyama Y et al.: Preliminary pharmacokinetics and pharmacodynamics of an ultra-short-acting opioid: remifentanil (GI87084B). Anesth Analg 1993; 77: 1031-1040.

12. Kapila A, Glass PS, Jacobs JR et al.: Measured context-sensitive half-times of remifentanil and alfentanil. Anesthesiology 1995; 83: 968-975.

13. Carabias P, Celades-Filella M, Zapardiel I, Alsina-Maqueda A, Genover-Llimona $E:$ 2014. Experience and results of office hysteroscopy at a primary hospital. J Obstet Gynaecol 2014; 34: 54-56. doi: 10.3109/01443615.2013.782277.

14. Gold MI, Watkins WD, Sung YF et al.: Remifentanil versus remifentanil/ midazolam for ambulatory surgery during monitored anesthesia care. Anesthesiology 1997; 87: 51-57.

15. Akcaboy ZN, Akcaboy EY, Albayrak D, Altinoren B, Dikmen B, Gogus N: Can remifentanil be a better choice than propofol for colonoscopy during monitored anesthesia care? Acta Anaesthesiol Scand 2006; 50: 736-741.

16. Servin FS1, Raeder JC, Merle JC et al.: Remifentanil sedation compared with propofol during regional anaesthesia. Acta Anaesthesiol Scand 2002; 46: 309-315.

17. Green $S M$, Roback MG, Krauss B: Emergency Department Ketamine Meta-analysis Study Group. Anticholinergics and ketamine sedation in children: a secondary analysis of atropine versus glycopyrrolate. Acad Emerg Med 2010; 17: 157-162. doi: 10.1111/j.15532712.2009.00634.x.

18. Badrinath S, Avramov MN, ShadrickM, Witt TR, Ivankovich AD: The use of a ketamine-propofol combination during monitored anesthesia care. Anesth Analg 2000; 90: 858-862.

19. Vasileiou I, Xanthos T, Koudouna E et al.: Propofol: A review of its nonanaesthetic effects. Eur J Pharmacol 2009; 605: 1-8. doi: 10.1016/j. ejphar.2009.01.007.

20. Akin A, Esmaoglu A, Guler G, Demircioglu R, Narin N, Boyaci A: Propofol and propofol-ketamine in pediatric patients undergoing cardiac catheterization. Pediatr Cardiol 2005; 26: 553-557.

21. Akin A, Esmaoglu A, Tosun Z, Gulcu N, Aydogan H, Boyaci A: Comparison of propofol with propofol-ketamine combination in pediatric patients undergoing auditory brainstem response testing. Int J Pediatr Otorhinolaryngol 2005; 69: 1541-1545.

22. Mildh L, Taittonen M, Leino K, Kirvelä O:The effect of low-dose ketamine on fentanyl-induced respiratory depression. Anaesthesia 1998; 53: 965-970.

\section{Corresponding author:}

Sema Oncul

Department of Anaesthesiology

Kocaeli Derince Education

and Research Hospital, Kocaeli, Turkey

e-mail:serdenish@yahoo.com

Received: 22.12.2014

Accepted: 30.09 .2015 